\title{
Gambaran Kesiapan Lansia dalam Menghadapi Masa Menopause di Kelurahan Wilayah Kerja Puskesmas Kesambi Kota Cirebon
}

\author{
Euis Lelly Rehkliana ${ }^{1}$ dan Lely Nurlaili ${ }^{2}$ \\ 1,2 Stikes Mahardika Cirebon \\ Coresponding Autor: elena19.mahardika@gmail.com
}

\begin{abstract}
Abstak: Masa menopause yaitu masa dimana terjadinya perubahan fisik dan psikologis. Masa ini memerlukan kesiapan yang cukup baik dari segi fisik maupun psikologisnya. Kesiapan atau ketidaksiapan seorang wanita pada saat menjelang menopause dapat dipengaruhi oleh rendah atau tingginya pengetahuan yang dimiliki tentang menopause. Tujuan penelitian ini yaitu untuk mengetahui kesiapan fisik, dan kesiapan psikologis wanita lansia dalam menghadapi masa menopause di kelurahan wilayah kerja Puskesmas Kesambi kota Cirebon. Jenis penelitian yang digunakan adalah deksriptif. Populasi dalam penelitian ini adalah wanita lansia usia antara 45-59 tahun di kelurahan wilayah kerja Puskesmas Kesambi kota Cirebon sebanyak 710 orang, pengambilan sampel menggunakan teknik accidental sampling dengan sampel sebanyak 88 responden. Pengukuran dilakukan dengan menggunakan kuesioner. Analisa yang digunakan menggunakan analisa univariat. Hasil penelitian menunjukkan bahwa dari 88 lansia yang siap secara fisik sebanyak 65 responden $(73,9 \%)$, tidak siap secara fisik 23 responden $(26,1 \%)$, sedangkan yang siap secara psikologis sebanyak 57 responden $(64,8 \%)$, tidak siap secara psikologis sebanyak 31 responden $(35,2 \%)$. Penelitian ini diharapkan dapat membantu meningkatkan kepercayaan diri wanita lansia karena menopause merupakan hal alamiah yang akan dialami oleh setiap wanita dan harus disyukurinya.

Kata Kunci: Kesiapan, Lansia, Menopause
\end{abstract}

\section{The Description of Adults Manage to Prepare During Menopause in Village of The Working Area Puskesmas Kesambi Cirebon City}

\author{
Euis Lelly Rehkliana ${ }^{1}$ and Lely Nurlaili ${ }^{2}$ \\ 1,2Stikes Mahardika Cirebon \\ Coresponding Autor: elena19.mahardika@gmail.com
}

\begin{abstract}
The menopause namely the where are the physical changes and psychological. The readness this requires a good enough in terms of the physical and phychological her. The readness or unpreparedness a woman at the time before menopause can be influenced by low or high knowledge owned about menopause. The purpose of this research is to know the readiness physical and the readiness psychological elderly woman in the face of the early in village of the working area puskesmas Kesambi Cirebon city. The kind of research used is descriptive. The population in this study is the elderly woman age between 45-59 years in the village the work of the health center Kesambi Cirebon city as much as 710 people,a sample of use a technique accidental sampling with a sample pf as much as 88 respondents.measurement done by using the questionnaire. Analysis of the used using analysis of the univariat. The results of the research the description of adults manage to prepare during menopause in village of the working area puskesmas Kesambi Cirebon can be categorized into physically prepared totally of 65 respondents $(73,9 \%)$, and mot ready physically, there were 23 respondents $(26,1 \%)$, while ready psychologically amount 57 respondents $(64,8 \%)$, don't psychologically ready amout 31 respondents $(35,2 \%)$. The research is expected to help increase the confidence of elderly women because menopause is a natural that will be experienced by every woman who should be grateful.
\end{abstract}

Keywords: Readiness, Elderly, Menopause

\section{A. PENDAHULUAN}

Jumlah penduduk Indonesia mencapai 203,47 juta jiwa yang terdiri dari 101,81 juta wanita dan diperkirakan telah memasuki usia menopause sebanyak 15,5 juta jiwa (15,2\%), dan pada tahun 2020 diperkirakan jumlah wanita yang hidup dengan usia menopause mencapai 30,3 juta jiwa (Bandiyah, 2009 dalam buku Sundari 2018). Jumlah penduduk di Jawa Barat berdasarkan jenis kelamin, laki-laki ada 24.652.609 jiwa dan perempuan ada 24.031.252 jiwa. Jumlah populasi perempuan usia 45-54 tahun adalah sebanyak 2.910.413 jiwa. Kini populasi di Jawa Barat sudah memasuki fase ageing population, dimana jumlah penduduk tua akan semakin banyak (Badan Statistik Provinsi Jawa Barat, 2018). Jumlah penduduk lansia kota Cirebon pada tahun 2018 di kelurahan wilayah kerja puskesmas Kesambi yaitu lakilaki usia antara 45-59 ada 707 jiwa dan perempuan ada 710 jiwa, usia $>60$ tahun ada 458 jiwa, dan usia $>70$ tahun ada 298 jiwa yang terdata dalam tujuh RW dan memiliki tujuh Posbindu yang diberi nama Posbindu Srikandi, Yudistira, Bougenville, Melati, Teratai, Mawar, dan Kenanga (Puskesmas Kesambi, 2019). 
Berdasarkan hasil studi pendahuluan pada Posbindu pada bulan maret di kelurahan wilayah kerja Puskesmas Kesambi sebanyak 1417 orang total jumlah lansia, dan 710 orang jumlah lansia perempuan. Adapun, beberapa yang mengalami gangguan psikologis terhadap kesiapan dalam menghadapi masa menopause seperti 25 orang merasa cemas (3,5\%), 595 orang merasa siap menghadapi menopause $(84 \%), 10$ orang merasa depresi (1,4\%), 30 orang merasa ada perubahan pada bagian fisik (4,2\%), dan 50 orang merasa ada gangguan pada pola tidur atau insomnia $(6,9 \%)$.

\section{B. METODE PENELITIAN}

Penelitian ini menggunakan jenis penelitian deskriptif. Penelitian deskriptif yaitu suatu metode penelitian yang di lakukan dengan tujuan utama untuk membuat gambaran atau mendeskripsikan tentang suatu keadaan secara objektif. Populasi yang dipakai dalam penelitian ini adalah wanita lansia berusia antara 45-59 tahun yang berjumlah 710 orang yang berada di kelurahan wilayah kerja Puskesmas Kesambi kota Cirebon.

Teknik sampling dalam penelitian ini adalah accidental sampling yaitu teknik penentuan sampel berdasarkan kebetulan atau konsumen yang secara kebetulan/insidental bertemu dengan peneliti yang dapat digunakan sebagai sampel, bila dipandang orang yang kebetulan ditemui itu cocok sebagai sumber data (Sugiyono, 2009). Agar karakteristik sampel tidak menyimpang dari populasinya, maka sebelum dilakukan pengambilan sampel perlu ditentukan kriteria inklusi, maupun eksklusi. Kriteria inklusi, meliputi : wanita lansia berusia 45-59 tahun, warga kelurahan Kesambi kota Cirebon, tinggal bersama keluarga, dan bersedia menjadi subjek penelitian. Kriteria eksklusi, meliputi : subjek dengan riwayat penyakit penyerta, tinggal seorang diri, tidak bersedia mengikuti penelitian dari tahap awal sampaiakhir.

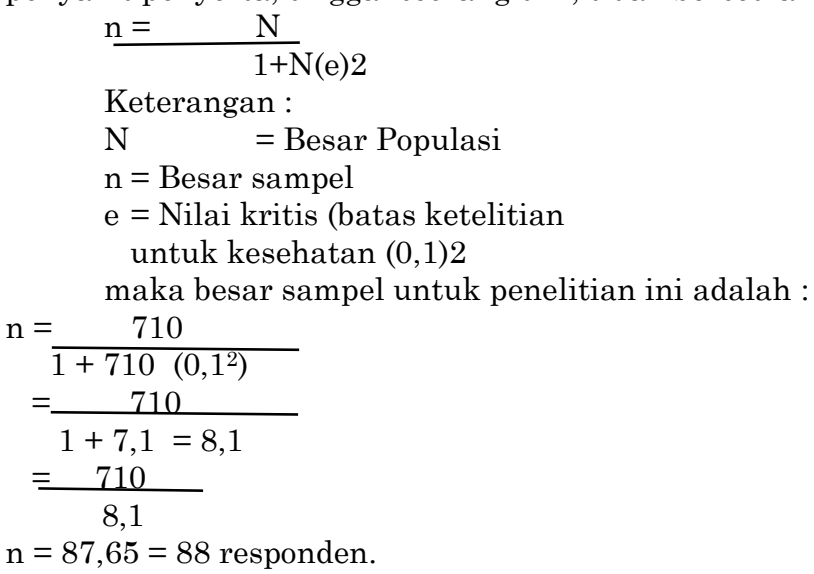

\section{HASIL DAN PEMBAHASAN}

Berikut disajikan hasil penelitian di Tabel 1.1 Distribusi Frekuensi Kesiapan Fisik Lansia dalam Menghadapi Masa Menopause di Kelurahan Wilayah Kerja Puskesmas Kesambi Kota Cirebon.

\begin{tabular}{llc}
\hline Kategori & Frekuensi & Presentase \\
\hline Siap & 65 & $73,9 \%$ \\
Tidak Siap & 23 & $26,1 \%$ \\
\hline Total & 88 & $100 \%$ \\
\hline
\end{tabular}


Tabel 1.2

Distribusi Frekuensi Kesiapan Psikologis Lansia dalam Menghadapi Masa Menopause di Kelurahan Wilayah Kerja Puskesmas Kesambi Kota Cirebon.

\begin{tabular}{llc}
\hline Kategori & Frekuensi & Presentase \\
\hline Siap & 57 & $64,8 \%$ \\
Tidak Siap & 31 & $35,2 \%$ \\
\hline Total & 88 & $100 \%$ \\
\hline
\end{tabular}

\section{PEMBAHASAN}

\section{Kesiapan Fisik Lansia dalam Menghadapi Perubahan Fisik di Masa Menopause}

Berdasarkan tabel 1.1 tentang distribusi frekuensi kesiapan fisik lansia dalam menghadapi masa menopause hasil penelitian menunjukan bahwa kesiapan lansia dalam menghadapi masa menopause di kelurahan wilayah kerja Puskesmas Kesambi kota Cirebon tahun 2019, responden yang merasa siap berjumlah 65 responden (73,9\%), tidak siap sebanyak 23 responden $(26,1 \%)$.

Menurut Slameto (2010), Kesiapan adalah keseluruhan kondisi seseorang yang membuatnya siap untuk memberikan respon atau jawaban dalam cara tertentu terhadap suatu situasi. Penyesuaian kondisi pada suatu saat akan berpengaruh atau kecenderungan untuk memberi respon. Kesiapan fisik berarti kesiapan seorang wanita untuk menghadapi perubahan fisik yang terjadi pada masa menopause (Muafira, 2018).

Terdapat beberapa hal yang sebaiknya dilakukan ketika wanita hendak memasuki masa menopause antara lain : Pertama, mengkonsumsi nutrisi yang tepat, beberapa nutrisi yang disarankan untuk dikonsumsi wanita yang akan menghadapi menopause diantarannya adalah : kalsium, asupan kalsium yang cukup (1200 sampai $1500 \mathrm{mg}$ perhari) dapat membantu menurunkan resiko osteoporosis serta mengurangi keluhan hot flushes. Kedua, melakukan yoga dan meditasi. Yoga pada saat pra menopause dapat mengurangi kecemasan dan membuat tubuh menjadi lebih rileks. Ketiga, menghentikan kebiasaan merokok, minum kopi, dan minumana beralkohol. Keempat, olahraga secara teratur, meski menopause adalah sesuatu yang alami, olahraga dapat membantu dalam mengatasi beberapa gejalagejala menopause. Kelima, melakukan kunjungan rutin ke petugas kesehatan (Muafira, 2018).

Dari hasil penelitian menurut Umi Rahmania Hidayaningtyas (2014), yang berjudul "Hubungan Kesiapan Menghadapi Menopause Dengan Tingkat Kecemasan Perempuan Menghadapi Menopause di Cabang Aisyiyah Kalikajar Kabupaten Wonosobo" hasil menunjukkan bahwa sebagian besar menunjukkan 20 responden (57,1\%) memiliki kesiapan cukup dan 23 orang (23\%) memiliki kecemasan ringan. Hasil korelasi antar variabel 0,045. Berdasarkan penelitian diatas ada persamaan dengan yang dilakukan oleh peneliti, hasil penelitian kesiapan fisik lansia dalam menghadapi masa menopause dikategorikan siap sebanyak 65 (73,9\%) yang dilakukan di Kelurahan Wilayah Kerja Puskesmas Kesambi Kota Cirebon.

Berdasarkan hasil penelitian diatas disimpulkan bahwa lansia sudah siap dalam menghadapi masa menopause, sehingga sudah dapat mendeteksi perubahan fisik yang terjadi menjelang menopause. Adapun program yang telah terlaksana sebagai peran tenaga kesehatan yang sudah maksimal dalam melakukan tugasnya yaitu dengan melakukan posbindu secara berkala dan sering melakukan konseling atau sesi tanya jawab pada lansia sehingga lansia merasa siap dalam menghadapi menopause yang akan dialaminya.

2. Kesiapan Psikologis Lansia dalam Menghadapi Perubahan Psikologis di Masa Menopause

Berdasarkan tabel 1.2 tentang distribusi frekuensi kesiapan psikologis lansia dalam menghadapi masa menopause hasil penelitian menunjukan bahwa kesiapan lansia dalam menghadapi masa menopause di kelurahan wilayah kerja Puskesmas Kesambi kota Cirebon, responden yang merasa siap berjumlah 57 responden $(64,8 \%)$, tidak siap sebanyak 31 responden $(35,2 \%)$.

Persiapan secara psikologis pada wanita yang akan menghadapi menopause : Pertama, Menghindari stress yaitu dengan cara Usahakan untuk membiasakan gaya hidup rileks dan menghindari tekanan yang dapat membebani pikiran. Hal ini penting untuk menghindari mengatasi dampak psikologis akibat menopause. Wanita yang memasuki masa menopause, tidak jarang merasa dirinya sudah tidak sempurna lagi sebagai seorang wanita. Kondisi ini sering menimbulkan tekanan psikologis. Jika tekanan ini tidak dapat diatasi akan berkembang menjadi stress yang berdampak buruk pada kehidupan sosial seorang wanita. Selain itu, stress atau keadaan tegang akan merangsang otak yang dapat menganggu keseimbangan hormon yang akibatnya berdampak pada kesehatan tubuh. Oleh karena itu, biasakan sejak dini untuk hidup lebih rileks atau jangan cemas dan mengatasi setiap masalah dengan cepat dan jalan terbaik. Kedua, Menopause dapat berjalan dengan lancar dengan adanya kemauan diri memandang hidup yang akan datang sebagai sebuah harapan yang membahagiakan, sehingga peristiwa yang dialami selalu dipandang dari segi yang baik. Hal tersebut 
dapat berlangsung bila ada dukungan dari orang sekitar, khususnya suami. Peran yang positif akan menumbuhkan perasaan bahwa kehadiranya masih sangat dibutuhkan oleh keluarga (Ismiyati, 2010). Dari hasil penelitian menurut Umi Rahmania Hidayaningtyas (2014), yang berjudul "Hubungan Kesiapan Menghadapi Menopause Dengan Tingkat Kecemasan Perempuan Menghadapi Menopause di Cabang Aisyiyah Kalikajar Kabupaten Wonosobo" hasil menunjukkan bahwa sebagian besar menunjukkan 20 responden $(57,1 \%)$ memiliki kesiapan cukup dan 23 orang (23\%) memiliki kecemasan ringan. Hasil korelasi antar variabel 0,045. Berdasarkan penelitian diatas ada persamaan dengan yang dilakukan oleh peneliti, hasil penelitian kesiapan psikologis lansia dalam menghadapi masa menopause dikategorikan siap sebanyak 57 responden (64,8\%) yang dilakukan di Kelurahan Wilayah Kerja Puskesmas Kesambi Kota Cirebon.

Dukungan keluarga ternyata sangat diperlukan wanita lansia dalam menghadapi masa menopause. Dukungan keluarga menjadikan seorang wanita yang menghadapi menopause menjadi sangat berharga dan menjadi ketentraman hidup.

Berdasarkan Arifahrahmi (2015) tentang pengalaman dan dukungan keluarga terhadap perubahan psikologis ibu menopause di Puskesmas Putri Ayu kota Jambi bahwa dukungan keluarga pada saat menopause sangat diperlukan karena wanita lansia akan merasa mendapat kepedulian, perlindungan, serta aman sehingga wanita lansia merasa diperhatikan, diterima dan dicintai. Dukungan dari seluruh anggota keluarga sangat besar artinya bagi kondisi kesehatan mental wanita yang mengalami menopause. Oleh sebab itu pendekatan fungsi keluarga sangat diperlukan dalam memberikan pelayanan kesehatan bagi wanita pada masa menopause (Prasetyawati, 2012).

\section{E. SIMPULAN}

Berdasarkan hasil penelitian yang diambil dengan judul "Gambaran Kesiapan Lansia dalam Menghadapi masa Menopause di Kelurahan Wilayah Kerja Puskesmas Kesambi Kota Cirebo", maka kesiapan responden dalam menghadapi masa menopause dapat disimpulkan sebagai berikut :

1. Kesiapan fisik lansia dalam menghadapi perubahan fisik masa menopause di kelurahan wilayah kerja Puskesmas Kesambi Kota Cirebon dikategorikan siap 65 responden (73,9\%).

2. Kesiapan psikologis lansia dalam menghadapi perubahan psikologis masa menopause di kelurahan wilayah kerja Puskesmas Kesambi Kota Cirebon dikategorikan siap 57 responden (64,8\%).

\section{F. SARAN}

Mengacu pada kesimpulan yang telah dikemukakan, ada beberapa saran yang diajukan dan diharapkan dapat dijadikan sebagai bahan pertimbangan.

1. Bagi Puskesmas Kesambi

- Sebagai masukan untuk upaya preventif dan promotif kepada masyarakat tentang kesiapan lansia dalam menghadapi masa menopause dan meningkatkan derajat kesehatan masyarakat.

- Diharapkan hasil penelitian ini dapat meningkatkan mutu pelayanan pada lansia di Puskesmas Kesambi dan sebagai bahan masukan bagi petugas kesehatan dalam memberikan konseling khususnya tentang perubahan fisiologis menghadapi masa menopause.

2. Bagi Institusi Pendidikan

- Diharapkan Institusi pendidikan menambah bahan bacaan yang terbaru khususnya yang berhubungan dengan menopause.

- Hasil penelitian sebagai bahan informasi tentang kesiapan lansia dalam menghadapi masa menopause dan pengembangan ilmu pengetahuan mahasiswa.

3. Bagi Responden

- Diharapkan wanita lansia untuk lebih meningkatkan kesiapanya dalam menghadapi masa menopause dengan rutin mengikuti posbindu untuk lansia atau konseling kepada tenaga kesehatan ataupun melalui media massa maupun media elektronik.

- Diharapkan wanita lansia agar tidak menganggap bahwa menopause adalah hal yang menakutkan, lebih mempersiapkan diri dalam menghadapi menopause dengan mengkonsumsi sayuran, buah-buahan susu dan tidak minum kopi. Tidak perlu cemas ataupun takut dalam menghadapi menopause karena menopause adalah sebuah siklus kehidupan yang pasti akan dialami oleh seorang wanita dan mampu mengkomuikasikan topik tentang menopause dengan tenaga kesehatan dan masyarakat tidak menganggap tabu lagi untuk membicarakannya agar masalah-masalah jelang menopause dapat diatasi dengan cara yang tepat.

4. Bagi peneliti lain

- Diharapkan melakukan penelitian lebih lanjut dengan pengembangan variabel penelitian dan jumlah responden yang lebih banyak sehinggga akan diperoleh hasil yang lebih baik.

- Penelitian ini dapat berguna sebagai bahan referensi untuk data dan pengembangan penelitian selanjutnya terkait tentang kesiapan lansia dalam menghadapi masa menopause. 


\section{G. DAFTAR PUSTAKA}

1. Ana Ratnawati. 2018. Asuhan Keperawatan Pada Pasien Dengan Gangguan Sistem Reproduksi. Yogyakarta : Pustaka Baru Press.

2. Atikah Proverawati dan Emi Sulistyawati. 2010. Menopause dan Sindrome Pramenopause. Yogyakarta : Nuha Medika.

3. Fatmah, S.K.M., M.Sc. 2010. Gizi Usia Lanjut. Jakarta : Gelora Aksara Pratama.

4. Fristiana Iriana. 2017. Metode Penelitian Terapan. Yogyakarta : Parama Ilmu.

5. Imelda Fitri, SST, M.Keb. 2016. Sistem Reproduksi Wanita. Yogyakarta : Nuha Medika.

6. Rudi Haryono. 2016. Siap Menghadapi Menstruasi dan Menopause. Yogyakarta : Gosyen Publishing.

7. Soekidjo Notoatmodjo. 2018. Metodologi Penelitian Kesehatan. Jakarta : Rineka Cipta.

8. Suharsimi Arikunto. 2014. Prosedur Penelitian Suatu Pendekatan Praktik. Jakarta : Rineka Cipta.

9. Sundari dan Dyah Pradnya Paramita. 2018. Klimakterium Masalah dan Penanganannya dalam Perspektif Kebidanan. Yogyakarta : Pustaka Baru. 